\title{
Investigation of Cyclodextrin Inclusion Compounds Using FT-IR, SEM and X-Ray Diffraction
}

\author{
S. Zidane, A. Maiza, H. Bouleghlem, W. Herizi, and S. Dahmani
}

\begin{abstract}
The prepared complexes of inclusion are characterized by IR where we have deduced the presence of new liaisons, this we permitted to say that, it has a formation of a new bands and we also concluded that the intensity of absorption of the majority of the frequencies are moved in the complexes which are weaker than in pure Tramadol. In the literature an amorphous material is more reactive than a crystalline one and as consequence amorphous materials are considered more hygroscopic when compared to crystalline solids. The results obtained by $\mathrm{X}$-rays shows a crystalline semi profile for the complexes prepared by the three methods contrary to Tramadol and $\beta-C D$ which present a crystalline profile. Modification of crystals and powder can be also observed by SEM and assumed as a proof of the formation of new inclusion complex.
\end{abstract}

Index Terms- $-\mathrm{B}-\mathrm{CD}$, cavity, inclusion, IR, SEM, solubility, tramadol.

\section{INTRODUCTION}

In recent years, the host-guest inclusion complexes are very much interest in wide fields of science and technology. Cyclodextrin (CD), a cyclic oligosaccharide containing six or more D (+) glucopyranose units (Scheme 1), it is one of the most important host compounds. A variety of guest compounds comprising ionic species, organic molecules and pharmaceutical drugs can be included in the cavity of CD in aqueous solutions. The CD inclusion compound is highly stereo specific, greatly stable and less toxic or nontoxic. Hence, CDs are widely investigated as enzyme models resolving agents for chiral compounds and molecular capsules of pharmaceutical drugs. It is of great interest, that CDs are able to form inclusion complexes more than one type. It is well known, CDs forming inclusion complex with various guests molecule with suitable polarity and dimension because of their special molecular structured internal hydrophobic cavity and external hydrophilic surface. In pharmaceutical more interest in CDs extends to enhance the solubility, chemical stability and bioavailability of poorly soluble drugs [1].

\footnotetext{
Manuscript received May 22, 2015; revised July 12, 2015.

S. Zidane, A.Maiza, W. Herizi, and S. Dahmani are with Laboratory of Electrochemistry, Molecular Engineering and Catalysis Redox LEIMCR University F. ABBAS 19000 Setif, Algeria (e-mail: zidanesabrina@yahoo.fr).

H. Bouleghlem is with Organic chemistry laboratory Applied (LCOA), Group of Chemistry Bioorganique Faculty of Science, Department of Chemistry. University Badji-Mokhtar 23000 Annaba, Algeria (e-mail: hocine_isc01@yahoo.fr).
}

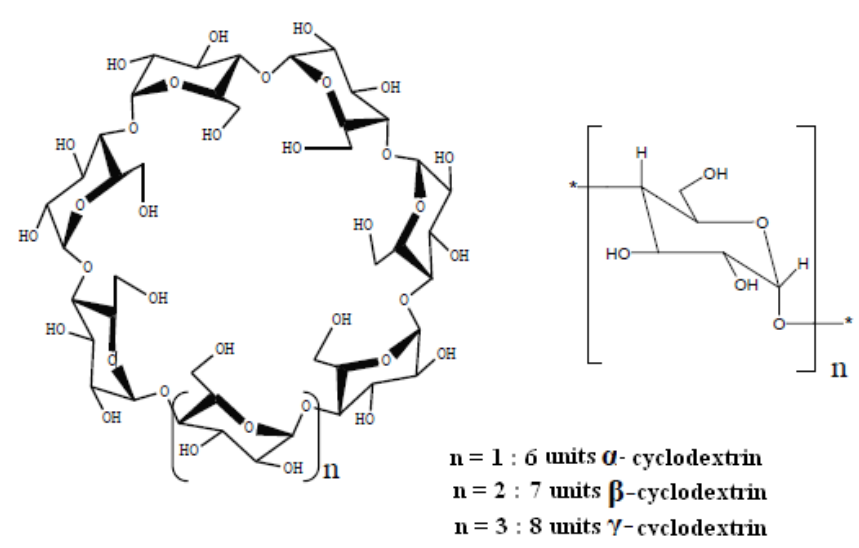

Scheme 1. Structure of $\alpha, \beta$, and $\gamma$ Cyclodextrins.

Tramadol drug is a typical opioid which is a centrally acting analgesic used for treating severe pain. It is a synthetic agent, as a 4-phenyl-piperidine analogue of codeine and appears to have actions on the GABAergic, noradrenergic and serotonergic systems [2]. Tramadol is a fine white powder which is practically insoluble in water. Tramadol is marketed as a racemic mixture with a weak affinity for the g-opioid receptor (approximately $1 / 6$ th that of morphine). The $(+)$ enantiomer is approximately four times more potent than the (+) enantiomer in terms of 1 -opioid receptor affinity and 5-HT reuptake, whereas the (-) enantiomer is responsible for noradrenalin reuptake effects [3]. These actions appear to produce a synergistic analgesic effect with (+) Tramadol exhibiting 1-10-fold higher analgesic activity than $(-)$ Tramadol (Scheme 2).

(a)<smiles>COc1cccc([C@]2(O)CCCC[C@H]2CN(C)C)c1</smiles>

(c)

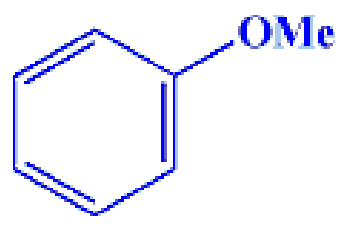

Scheme 2. Structure of (a) (+) Tramadol, (b) (-) Tramadol, (c) Anisole. 
In this work, we investigate the complexes prepared containing Tramadol and $\beta$-cyclodextrin, by the use of IR, SEM and X-ray diffraction with an aim of having more information for the complexes of inclusion and for the solubility of Tramadol.

\section{EXPERIMENTAL}

\section{A. Phase Solubility Study}

Phase solubility studies were performed by the method of Higuchi and Cannors [4]. $5 \mathrm{mg}$ of Tramadol is placed in closed flasks, containing $15 \mathrm{~mL}$ of a $\beta$-CD solution at different molar concentrations $(0 ; 3 ; 6 ; 9 ; 12 ; 15 \mathrm{mM})$. The contents were stirred for $72 \mathrm{~h}$ at $37^{\circ} \mathrm{C}$. The time duration was fixed based on pilot experiment and found to be sufficient to achieve equilibrium of mixture.

After sample filtration, dilute solutions were prepared and analyzed by the use of UV spectrophotometer.

\section{B. Preparation of the Complexes}

The complexes containing $\beta-C D$ and Tramadol were prepared in the molar relationship (1/1) with three different methods which are:

\section{1) Physical mixture}

We introduced $1.135 \mathrm{~g}$ of $\beta-\mathrm{CD}$ (molecule host) into $1 \mathrm{~mL}$ of methanol in a mortar of ceramics and we added $0.2977 \mathrm{~g}$ of Tramadol (molecule guest) by portion and we mixed the whole during $45 \mathrm{~min}$, during this process, a quantity of a hydroalcoolic solution (water-methanol) is added. The complex produced ( $\beta$-CD:Tram M) left in the drying oven until drying total [5].

\section{2) Molar mixture}

While, for the molar mixture, we prepared two solutions, one of Tramadol and the other of $\beta-C D$, these solutions were prepared beforehand separately.

\section{a) Solution of Tramadol}

We dissolved $0.2104 \mathrm{~g}$ of Tramadol in $500 \mathrm{~mL}$ of distilled water.

\section{b) $\beta$-CD solution}

We dissolved $0.908 \mathrm{~g}$ of $\beta-\mathrm{CD}$ in $500 \mathrm{~mL}$ of distilled water. These two solutions were agitated at a temperature $40^{\circ} \mathrm{C}$ using an agitator until total dissolution, after we mixed and left these two solutions agitated during $3 \mathrm{~h}$, after the agitation we put this mixture in a hermetically closed container and we have met the mixture in the freezer, after congelation we defrosted this mixture using a drying oven. After we recovered the finished product ( $\beta-\mathrm{CD}$ :Tram $\mathrm{MM}$ ) resulting from this method by a total evaporation of the solvent (distilled water) [6].

\section{3) Microwave irradiation method}

This technique involves the microwave irradiation reaction between drug and complexing agent using a microwave domestic (LG marks). The Tramadol and $\beta-\mathrm{CD}$ are dissolved in a mixture of water and organic solvent in a specified proportion into a round bottom flask. The mixture is reacted for short time of about one to two minutes at $60^{\circ} \mathrm{C}$ in the microwave oven at $350 \mathrm{Watt}$. After the completion of reaction, the precipitate so obtained ( $\beta$-CD:Tram MO) is separated using Whatman filter paper, and dried in vaccum oven. Microwave irradiation method is a novel method for industrial scale preparation due to its major advantage of shorter reaction time and higher yield of the product [7].

\section{INSTRUMENTS}

FT-IR spectra were obtained with Fourier transforms infrared spectroscopy to Meter FTIR-8300; the $\mathrm{KBr}$ beamsplitter limited the spectral range $4000-400 \mathrm{~cm}^{-1}$. The surface morphology of pure components and their equimolar binary systems obtained by irradiation of microwave were examined by means of a JEOL (JSM -700 1F Field Emission) scanning electron microscope. X-Ray powder diffraction patterns were recorded at room temperature using expert Pro 2006 , cathode in coppers, $\lambda=1,54 \AA, \mathrm{V}=40 \mathrm{kV}, \mathrm{I}=20 \mathrm{~mA}$, with scanning speed of $4 \theta$ per min over a $2 \theta$ range of $4^{\circ}$ to $60^{\circ}$.

UV spectrophotometer utilized was of Model Jenway 6305 UV/Visible range Spectrophotometer (190-1000nm).

\section{RESULTS AND DISCUSSIONS}

\section{A. Phase Solubility}

The analysis of the phase solubility is among the preliminary requirements for optimizing the development of the inclusion complexes of drugs which can be used for evaluating the affinity between the CDs and the drug in water.

While CDs are known to generate aggregates (selfassociates) in aqueous solvents, [8], [9] the method is widely used for the determination of the molar ration in drug-CD complexes with CDs. The curve of Tramadol solubility phase showed an increase in the solubility of Tramadol with increasing concentrations of $\beta-\mathrm{CD}$ in water to the concentration $6 \mathrm{mM}$ then there has been a decrease in the solubility with the increasing concentrations of $\beta$-CD in water (Fig. 1). The curve of the solubility phase showed Bs type solubility curve for $\beta-C D$, the Bs profile follows from $A L$ profile (linear) are generally attributed to the formation of complexes 1: 1 and then from a particular point $(6 \mathrm{mM})$, any addition of $\beta$-cyclodextrin leads to precipitation of the complex with the appearance of a plateau (as the complex precipitates, the active ingredient not dissolved yet, dissolved in free form ), the curve then decreases (any excess of active ingredient is dissolved and the free fraction is gradually complexed and precipitated.

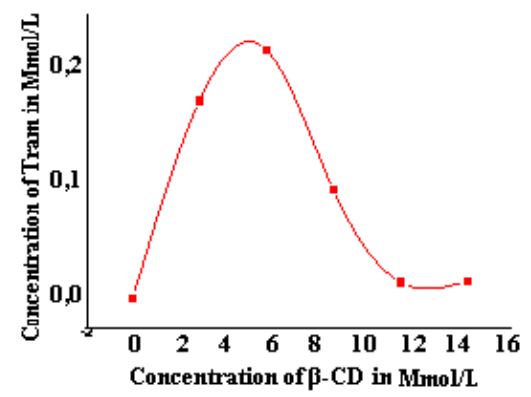

Fig. 1. Phase solubility curve of Tramadol in aqueous solution of $\beta-\mathrm{CD}$ at $37^{\circ} \mathrm{C}$.

The stability constants ( Ks) for the complex at $37^{\circ} \mathrm{C}$, assuming a 1: 1 stoichiometry, calculated from the slope of the preliminary part of the straight line of the solubility curve 
is $1922.22 \mathrm{M}^{-1}$ which indicates the formation of stable complex, since $\mathrm{Ks}$ in the range of $200-5000 \mathrm{M}^{-1}$ indicates a good complexing capacity. This also suggests that there is an increase in the dissolution profile which would certainly increase the bioavailability of Tramadol but at low concentration of $\beta-\mathrm{CD}$.

\section{B. FT-IR Spectral Studies}

Host: guest interaction in a complex of inclusion is attenuated by weak forces between the molecules such as bonds of hydrogen and hydrophobic interaction [10]. The figure (Fig. 2) present absorption spectra in IR for $\beta-C D$, Tramadol, $(\beta-\mathrm{CD}$ :Tram $\mathrm{M}), \quad(\beta-\mathrm{CD}$ :Tram MM) and $(\beta-C D$ :Tram MO).

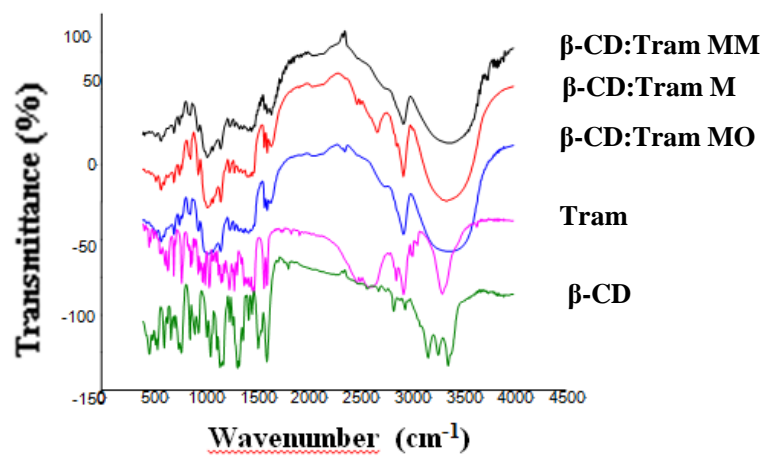

Fig. 2. FTIR spectra for $\beta$-CD, Tramadol, ( $\beta$-CD:Tram M), ( $\beta$-CD:Tram $\mathrm{MM})$, and ( $\beta$-CD:Tram MO).

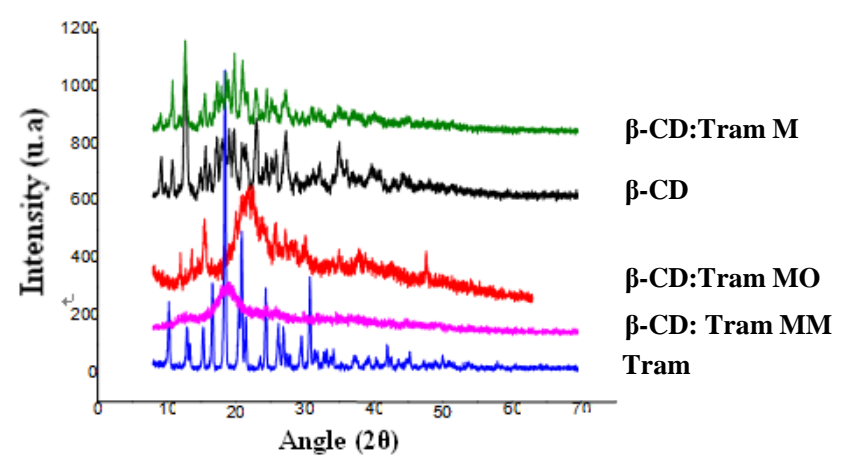

Fig. 3. XRD diffractogram of $\beta-C D$, Tramadol, ( $\beta$-CD:Tram $M)$, $(\beta-C D: T r a m ~ M M)$ and ( $\beta-C D$ :Tram MO).

According to the result obtained, we deduced the presence of a new bands, this will allow us to say that there is a formation of the complex. Tramadol with an absorption band around $3305,8 \mathrm{~cm}^{-1}$. This band represents the intermolecular hydrogen band and in the complexes of inclusion this band is shifted around $3348,2 \mathrm{~cm}^{-1}$ (Fig. 1). The $(-\mathrm{CH})$ aromatic of pure drug appears around $2927 \mathrm{~cm}^{-1}$ and $2815,9 \mathrm{~cm}^{-1}$ these two frequencies are lost in the complexes. The frequency of the aromatic cycle of the pure drug appears around 1604,7; 1577,$7 ; 1418,21434,9 \mathrm{~cm}^{-1}$, on the other hand these frequency are very low 1608,$5 ; 1581,5 ; 1647,1 \mathrm{~cm}^{-1}$ in the complexes of inclusion. The band of $\left(-\mathrm{OCH}_{3}\right.$ of Tramadol) appears around $1110 \mathrm{~cm}^{-1}$ in pure drug while it is lost in the complex. The frequency of band of $\mathrm{N}-\mathrm{CH}_{3} \mathrm{HCl}$ appears around $2607,6 \mathrm{~cm}^{-1}$ is also lost in the complexes, we concluded that the intensity of absorption of the majority of the frequencies are moved in the complexes of inclusion which are weaker than in pure Tramadol. These results indicate that the amino group is present in the absorbent part and the anisole group of Tramadol is encapsulated in the
$\beta$-CD cavity. It can also be observed that the inclusion compounds' spectra are very similar to each other, implying the three techniques used to obtain $\beta$-CD:Tram are suitable to provide inclusion complexes.

\section{RX Spectral Studies}

In the literature, the difference in the solid phases is responsible for the differences in the solubility of the drugs, for example an amorphous substance is more hygroscopic and more reactive than a crystalline substance due to its more raised thermodynamic activity [11]. The studies by the X-ray are very useful in order to determine these properties. The Diagrams of diffraction of X-Rays of $\beta-C D$, Tramadol, $(\beta-\mathrm{CD}$ :Tram $\mathrm{M}),(\beta-\mathrm{CD}:$ Tram MM), and ( $\beta$-CD:Tram MO) are shown in Fig. 3, the results obtained shows a crystalline semi profile for the complexes of inclusion obtained by the three methods contrary to Tramadol and $\beta-C D$ which present a crystalline profile. Crystallinity and amorphicity are important factors that must be related to compounds' solubility [12]. However, they are useful to monitor the compounds' crystallinity changes upon host-guest interaction.

\section{Microscopic Morphological Observation}

Scanning Electron Microscopy (SEM) was performed for the raw materials and the complex obtained implying the microwave irradiation in order to investigate the morphology modification and the results are depicted in Fig. 4, we observed a powder form of Tramadol and $\beta$-CD by scanning electron microscope and then we saw a powder form of the inclusion complex. Pictures clearly elucidated the difference in each case. The inclusion complex structure is different from $\beta-C D$ and Tramadol pure. Modification of crystals and powder can be assumed as a proof of the formation of new inclusion complex.
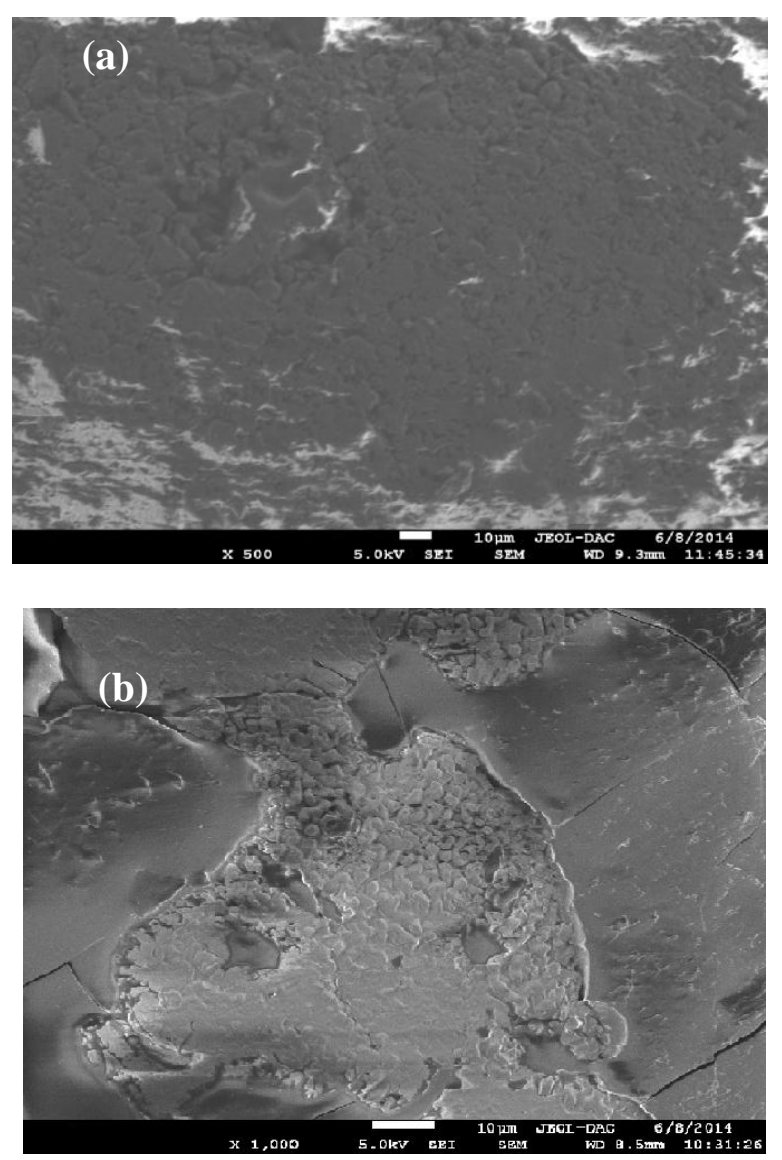

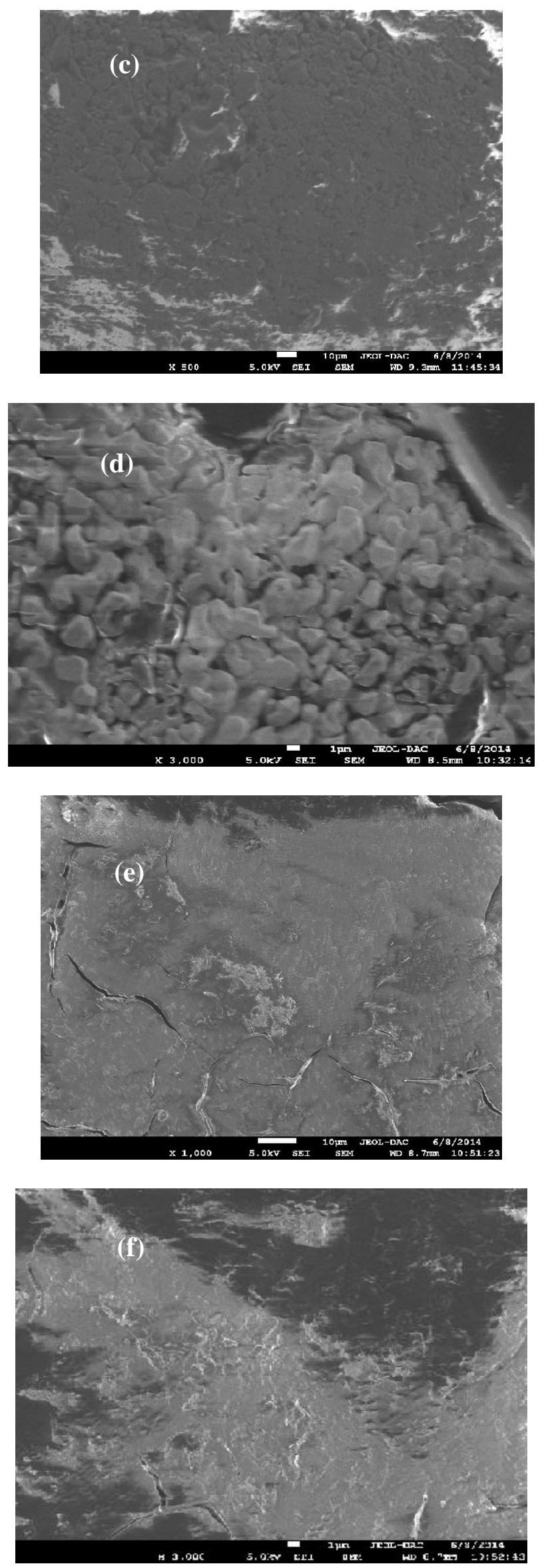

Fig. 4. Scanning electron microscope photographs of (a) Tramadol $(500 \times),(b)$ Tramadol $(1000 \times),(c)$ ( $\beta-\mathrm{CD}$ :Tramadol MO) $(500 \times),(\mathrm{d})(\beta$ $-\mathrm{CD}$ :Tramadol MO) (3000×), (e) $\beta-\mathrm{CD}(1000 \times)$ and (f) $\beta-\mathrm{CD}(3000 \times)$.

\section{CONCLUSION}

Based on the results obtained, we can conclude that the methods proposed in this work are effective for obtaining a complex ( $\beta$-CD:Tramadol), l'IR confirm the formation of a complex of inclusion. Free Tramadol changed the crystalline size and morphology by the introduction of $\beta$-CD. In consequence of increased solubility, that returns CDs an important pharmaceutical excipient.

Improving the pharmaceutical effect of drugs in the formulation ( $\beta$-CD:PA) was to be related to an improvement in the oral bioavailability as a consequence of the increased solubility, the study of the solubility of Tramadol showed limited solubility with increasing concentration of $\beta-\mathrm{CD}$,

\section{REFERENCES}

[1] W. Saenger and A. Angew, Chem Int Ed Engl, vol. 19, pp. 334 -362, 1980.

[2] A. Anton Smith, R. Manavalan, K. Kannan, and N. Rajendiran, "Spectral characteristics of tramadol in different solvents and $\beta$-cyclodextrin," Spectrochimica ACTA Part A, vol. 74, pp. 469-477, 2009.

[3] E. A. Shipon, "Tramadol-present and future," Anaesth. Intens. Care, vol. 28, pp. 363-380, 2000.

[4] T. Higuchi and K. Connors, "Phase solubility techniques," Adv Anal Chem Instru, vol. 4, pp.17-123, 1965.

[5] J. S. Patil, D. V. Kadam, S. C. Marapur, and M. V. Kamalapur, "Inclusion complex system: A novel technique to improve the solubility and bioavailability of poorly soluble drugs a review," Int $J$ Pharm. Sci Rev Res, vol. 2, pp. 29-34, 2010.

[6] X. Zhang, "Piroxicam 2-hydroxypropyl- $\beta$-cyclodextrin inclusion complex prepared by a new fluid-bed coating technique," Journal of Pharmaceutical Sciences, vol. 98, pp.665-675, 2009.

[7] V. A. Saharan, V. Kukkar, M. Kataria, M. Gera, and P. K. Choudhary, "Dissolution enhancement of drugs," Part I. Technologies and Effect of carriers. Int J Health Res, vol. 2, pp. 107-124, 2009.

[8] T. Loftsson, A. Magnusdottir, and M. Masson, and J. F. Sigurjonsdottir, "Self-association, and cyclodextrin solubilization of drugs," J. Pharm Sci., vol 91, pp. 2307-2323, 2002.

[9] N. K. Rajesh and B. S Kucherkar, "Preparation, physicochemical characterization, dissolution and formulation studies of telmisartan cyclodextrin inclusion complexes," Asian Journal of Pharmaceuticals, vol 41, pp. 52-59, 2010.

[10] M. A. Silva Pires, R. A. Souza Dos Santos, and R. D. Sinisterra, "Pharmaceutical composition of hydrochlorothiazide: $\beta-C D$ : preparation by three different methods, physico-chemical characterization and in vivo diuretic activity evaluation," Molecules, vol. 16, pp. 4482-4499, 2011.

[11] G. G. Z. Zhanga, D. Lawa, E. A. Schmittb, and Y. Qiub, "Phase transformation considerations during process development and manufacture of solid oral dosage forms," Adv. Drug Deliv. Rev, vol. 56, pp. 371-390, 2004.

[12] X. Zang, D. Wu, J. Lai, Y. Lu, Z. Yin, and W. Wu, "Piroxican/2-hydroxypropyl- $\beta$-cyclodextrin inclusion complex prepared by a new fluid-bed coating techning," J. Pharm. Sci, vol. 98 , pp. 665-675, 2009.

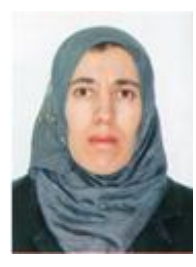

Salima Zidane was born in El Eulma Sétif Algeria on November 14, 1980. She is an assistant professor in pharmaceutical engineering and a research professor at the University of Mohamed Boudiaf, Msila Algeria since 2007. Ms Salima is a member of the Research Laboratory of Electrochemistry, Molecular Engineering and Catalysis Redox LEIMCR University, $\mathrm{F}$. ABBAS-19000 Setif, Algeria and She is a member of the Research Project: Study of Structural Composite Nano-Based Copolymers under code $N^{\circ}$. J0105620120029, University of Mohamed Boudiaf Msila. 